\title{
A poesia negra de Harryette Mullen em tradução: (des)encontros com o leitor
}

Lauro Maia Amorim

Resumo: Com base em quatro poemas da autora afro-americana contemporânea Harryette Mullen, por mim traduzidos para o português, e nas questões suscitadas por sua obra, este trabalho investiga as seguintes questões: quais seriam os desafios de se traduzir sua poesia, levando-se em consideração os lugares discursivos dos leitores identificados ou não com a estética literária afro-brasileira? Essa (não-) identificação exerceria alguma influência no modo como sua poesia poderia ser lida em tradução? Assim, neste trabalho, busca-se contrastar as questões raciais e estéticas que fundamentam a visão de Mullen a respeito de sua poesia e de seu público-leitor (imaginado) com as questões de público-alvo, contextualmente diversas, que minhas traduções de seus poemas requerem "imaginar" no âmbito das relações sócio-raciais brasileiras.

Palavras-chave: tradução, poesia, negritude, experimentação, públicoleitor

Com base em quatro poemas da autora afro-americana contemporânea Harryette Mullen, por mim traduzidos para o português, e nas questões suscitadas por sua obra, procuro investigar as seguintes questões: quais seriam os desafios de se traduzir sua poesia, levando-se em consideração os lugares discursivos dos leitores 
Lauro Maia Amorim. A poesia negra de Harryette Mullen em tradução: ...

identificados ou não com a estética literária afro-brasileira? Essa (não-) identificação exerceria alguma influência no modo como sua poesia poderia ser lida em tradução?

Mullen apresenta-nos um tipo de texto em que se destacam procedimentos como o deslocamento dos limites relativos aos clichês das relações estético-raciais, por meio de alusões à cultura afro-americana e a seus conflitos internos, como também à cultura globalizada na qual se vê implicada. De modo geral, sua poesia explora os signos da cultura americana, por meio de referências aos saberes da mídia e da cultura pop, e de experimentações com o jazz, o blues e a cultura hip-hop. Acerca de sua poética, Elizabeth Frost (2000) afirma que:

[...] cruzando fronteiras entre campos estéticos frequentemente isolados, Harryette Mullen é pioneira de sua própria forma de poesia lírica disjuntiva e bluseada, combinando preocupações com questões suscitadas por políticas de identidade com ênfase pós-estruturalista na linguagem. Mullen desafia as opiniões predominantes acerca dos cânones da poesia contemporânea, buscando chamar atenção, em especial, para as tradições marginalizadas do experimentalismo afro-americano do qual sua escrita emerge. As influências sobre seu trabalho incluem desde Gertrude Stein ao Black Arts Movement, de Sapho a Bessie Smith, do movimento Language poetry ao rap. Os textos lúdicos e alusivos de Mullen vêm atraindo uma atenção cada vez maior nos últimos anos, talvez pelo próprio fato de que eles sejam, com frequência, difíceis de categorizar. Em seu modo particular de abordar a poética, Mullen promove importantes interrogações acerca da tradição, da inovação e da identidade cultural. (p. 397) ${ }^{1}$

\footnotetext{
Todas as citações em inglês foram por mim traduzidas.
} 
Em Muse \& Drudge ${ }^{2}$, obra composta de oitenta poemas sem títulos e dispostos formalmente em quatro quartetos, um verso do primeiro poema parece ser uma referência intertextual a uma canção de blues tradicional, "Sapphire's lyre styles." "Saphire" pode ser lida como uma alusão a Sapho e a sua lira, possivelmente a primeira grande poetisa do mundo ocidental, que viveu na ilha de Lesbos, na Grécia Antiga:

Sapphire's lyre styles

plucked eyebrows

bow lips and legs

whose lives are lonely too

my last nerve's lucid music sure chewed up the juicy fruit you must don't like my peaches there's some left on the tree

you've had my thrills

a reefer a tub of gin

don't mess with me I'm evil

$I^{\prime} m$ in your sin

clipped bird eclipsed moon soon no memory of you no drive or desire survives you flutter invisible still

(MULLEN, 2006, p. 99)
Sapphira seu estilo sua lira sobrancelhas dedilhadas

lábios e pernas de arco

cujas vidas também são sós

minha lúcida música de fibra finda sugando da fruta o que há ainda meus pêssegos não você não vai gostar ainda resta algum no pé pra apanhar

você tem meu arrepio e tal um barril de gim e um baseado cuidado comigo que eu sou o mal sou eu no seu pecado

pássaro sem asa eclipsada lua não demora, nenhuma memória sua desejo e impulso que falecem você invisível frêmito que flutua

Já os versos “you must don't like my peaches/there's some left on the tree" podem ser lidos como uma alusão ao verso de uma canção tradicional do blues, "Mama's Got the Blues", cantada por

2 A obra Muse \& Drudge foi publicada em 1995 pela editora Singing Horse Press, mas atualmente é editada apenas pela Graywolf Press, em coletânea intitulada Recyclopedia (2006), que contém duas outras obras anteriores da autora, $S^{*} P e R m^{* *} K^{*} T$ (1992) e Trimmings (1991). Mullen teve o primeiro trabalho de poesia, Tree Tall Woman, publicado em 1981, considerado menos experimental que os demais, e mais diretamente influenciado pelo movimento estético-político do Black Arts Movement. 
Lauro Maia Amorim. A poesia negra de Harryette Mullen em tradução: ...

célebres figuras como Bessie Smith e Ma Raney: “[...] I got a man in Atlanta, two in Alabama, three in Chattanooga, four in Cincinnati, five in Mississippi, six in Memphis, Tennessee. If you don't like my peaches, please let my orchard be!" A experimentação formal em Muse \& Drudge revela a influência do estilo criptográfico da poesia de Gertrude Stein e do Language poetry, mas sempre imbuída de uma relação crítica com questões de identidade cultural, envolvendo, inclusive, o tema da miscigenação e da origem, como no poema "O rosy so drowsy in":

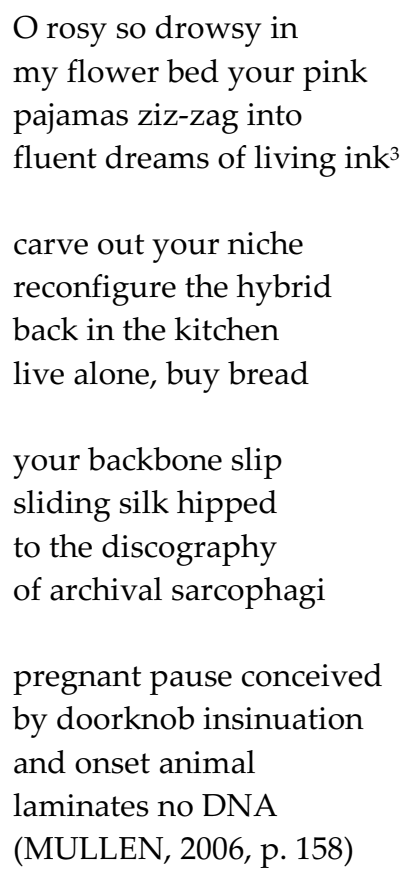

\author{
Ô rósea tão manhosa na \\ minha cama em flores o teu \\ pijama rosa faz ziguezague \\ em sonhos fluidos de preto choque \\ esculpe o teu nicho \\ reconfigura o híbrido \\ de volta à cozinha \\ vive só, compra pão \\ tua coluna desliza \\ requebra suave em seda \\ à discografia \\ da sarcofagia arquival \\ pausa prenhe concebida \\ por insinuação de maçaneta \\ adan dando \\ o DNA d nada
}

Os dois últimos versos representam um palíndromo, de modo que "and onset animal" ("e o animal do começo"), lido de trás para frente, corresponde a "laminates no DNA" ("não lamina nenhum

3 "Ink," além de "tinta", também pode significar a "cor preta", que se contrasta com "pink", a cor rosada da pele de certas pessoas brancas. 
DNA"). A tradução, por sua vez, também valeu-se deste procedimento: "adan dando" sugere o nome de Adão, como o "primeiro animal, o do começo," que lido de trás para frente é "O DNA d nada." Atualmente, sabe-se que o DNA está na origem das discussões tanto éticas quanto étnicas que procuram explicar as "misturas raciais", ou melhor, a heterogeneidade genética de que se compõe qualquer indivíduo. O poema reiteraria, portanto, essa questão, desconstruindo a fantasia da pureza racial, já que o DNA não carregaria origens puras. Nessa perspectiva, também se destaca outro poema, de caráter heteroglóssico, que faz, do encontro entre o espanhol e o inglês, o caminho para o reconhecimento da condição mestiça do sujeito, "virgem de origens:"

mulatos en el mole me gusta mi posole hijita del pueblo moreno ya baila la conquista

chant frantic demands in the language bring generic offerings to a virgin of origins

yes I've tried in vain never no more to call your name and in spite of all reminders misremembered who I am

ghosts brush past ${ }^{4}$ surprise arrival at these states of flux that flow and flabbergast (MULLEN, 2006, p. 165) mulatos en el mole me gusta meu posole filhinha del pueblo moreno ya baila la conquista

canta frenéticas demandas na língua traga genéricas oferendas a uma virgem de origens

sim, eu tentei em vão nunca jamais chamar teu nome e apesar de todos os lembretes deslembrei-me de quem sou

fantasmas despassam o passado surpresa chegada a esses estados de fluxo que fluem e pasmam

4 "Brush past by someone": passar furtivamente por alguém para não ser notado. 
Lauro Maia Amorim. A poesia negra de Harryette Mullen em tradução: ...

"Sleeping with the Dictionary" é o poema de seu livro homônimo, lançado em 2002, e que explora os papéis do dicionário na formulação poética e na própria constituição do poeta em si mesmo:

Sleeping with the Dictionary

I beg to dicker with my silver-tongued companion, whose lips are ready to read my shining gloss. A versatile partner, conversant and well-versed in the verbal art, the dictionary is not averse to the solitary habits of the curiously wide-awake reader. In the dark night's insomnia, the book is a stimulating sedative, awakening my tired imagination to the hypnagogic trance of language. Retiring to the canopy of the bedroom, turning on the bedside light, taking the big dictionary to bed, clutching the unabridged bulk, heavy with the weight of all the meanings between these covers, smoothing the thin sheets, thick with accented syllables - all are exercises in the conscious regimen of dreamers, who toss words on their tongues while turning illuminated pages. To go through all these motions and procedures, groping in the dark of an alluring word, is the poet's nocturnal mission. Aroused by myriad possibilities, we try out the most perverse positions in the practice of our nightly act, the penetration of the denotative body of the work. Any exit from the logic of language might be an entry in a symptomatic dictionary. The alphabetical order of this amble block of knowledge might render a dense a lexicon of lucid hallucinations. Beside the bed, a pad lies open to record the meandering of migratory words. In the rapid eye movement of the poet's night vision, this dictum can be decoded, like the secret acrostic of a lover's name.

(MULLEN, 2002, p. 67)
Dormindo com o dicionário

Imploro para bater boca com minha eloquente companhia cujos lábios estão prontos para ler minha glosa brilhante. Um companheiro versátil, fluente e bem versado na arte verbal, o dicionário não é avesso aos hábitos solitários do leitor curiosamente desperto. Na escuridão da insônia noturna, o livro é estimulante sedativo, despertando-me a cansada imaginação ao transe hipnagógico da língua. Retirar-se ao dossel da cama, ligar a luz do criado, levar o grande dicionário à cama, agarrar-se ao volume integral, pesado com o peso de todos os significados entre capas, amaciar os lençóis finos, engrossados com sílabas acentuadas - são todos exercícios no regime consciente dos sonhadores, a jogar cara e coroa com palavras nas línguas enquanto viram páginas iluminadas. Se submeter a todos esses procedimentos e moções, passando a mão no escuro da palavra sedutora, é a missão noturna do poeta. Excitados por possibilidades miríades, experimentamos as posições mais perversas na prática de nosso gesto noturnal, a penetração do corpo denotativo da obra. Qualquer saída da lógica da língua pode ser uma entrada em um dicionário sintomático. A ordem alfabética desse âmbulo bloco do saber pode traduzir densos léxicos de lúcidas alucinações. À beira da cama, um caderno se abre para gravar os meandros de palavras migrantes. No movimento rápido do olho da visão noturna do poeta, o dictum pode ser decodificado, como o acróstico secreto do nome do amante.

Se é verdade que um dicionário desperta "possibilidades miríades" de criação e liberação na relação mais íntima que o poeta pode desenvolver com ele, não será menos verdade que essa relação implica alguma forma de penetração, enredamento, senão aprisio- 
namento. Ao dormir com o "dic-" (referência possível ao "dick," "pênis") do dictionary, o poeta é penetrado pela herança, tanto quanto ele penetra o corpo de significados, valores e definições herdados do dicionário. O poeta, tradutor por excelência, traduz a si mesmo no corpo de seu trabalho. Seu próprio corpo é traduzido pela herança desse dicionário passado e presente, esmagadoramente virtual, sem papel, que é concebido por meio de seu trabalho. Se a busca pela liberdade e pela liberação deve ser perseguida nas possibilidades infinitas da criatividade, isso só pode se dar no interior de uma lógica mais abrangente que aprisiona a infinitude de se redefinir a própria identidade: "qualquer saída da lógica da língua pode ser uma entrada em um dicionário sintomático." A ordem alfabética deve garantir a organização das entradas, ou das múltiplas penetrações que levarão o poeta ao prazer, senão à dor e à alucinação, mas, paradoxalmente, no interior da lucidez e do controle: "a ordem alfabética desse âmbulo bloco do saber pode traduzir densos léxicos de lúcidas alucinações." De que modo, portanto, a poética de Mullen se enreda, na tradução, com questões de recepção no contexto brasileiro?

\section{A poesia de Harryette Mullen, a negritude e o público- leitor nos EUA}

Enquanto leitor da poesia de Mullen - um leitor que não é norte-americano e cuja formação cultural foi construída em um universo no qual a complexidade social é particular de uma nação cultural e biologicamente miscigenada, como é o Brasil - senti-me atraído por seu interesse em repensar criticamente noções preconcebidas a respeito da estética literária afro-americana. Tais noções, ou melhor, expectativas, têm efeitos que poderiam ser interpretados, em certa medida, como uma forma de segregação estética: ou o autor negro escreve de acordo com as expectativas (advindas, por exemplo, de grandes editoras, como também de certos leitores, incluindo negros e/ou brancos) em torno de como a poesia negra deve se ex-

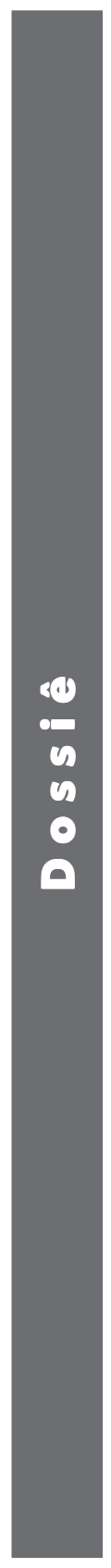


Lauro Maia Amorim. A poesia negra de Harryette Mullen em tradução: ...

pressar, ou seu trabalho pode ser condenado ao ostracismo. Ou, ainda, pode ser que o autor jamais seja considerado um "autêntico artista negro", seja do ponto de vista dos negros ou dos brancos. Mullen, no entanto, problematiza o que geralmente se considera "authentic blackness", na medida em que sua poesia, aliada ao seu discurso como pesquisadora, tem promovido um engajamento interessante com a tradição afro-americana ao levantar questões provocantes sobre as condições que definem o que "deve ser" a poesia negra. Nesse sentido, de acordo com Cynthia Hogue (1999),

Harryette Mullen preocupa-se com a diversificação da estética predominante da "acessibilidade" que caracteriza a poesia e a crítica afro-americanas. E Elizabeth Frost considera seu livro Muse E Drudge um "híbrido poético" que recorre tanto à Stein quanto ao blues, entre outras influências - um longo poema lírico que explora "as influências e as linguagens diversas de uma cultura miscigenada."

Nesse sentido, é válido contrastar as questões raciais e estéticas que fundamentam a visão de Mullen a respeito de sua poesia e de seu público-leitor (imaginado) com as questões de público-alvo, contextualmente diversas, que minhas traduções de seus poemas requerem "imaginar" no âmbito das relações sócio-raciais brasileiras. No entanto, antes de tratar dos desafios que a tradução de sua poesia representa, convém explorar os conflitos que seu trabalho tem suscitado especialmente em face de seu público-leitor nos EUA.

Um dos aspectos mais tradicionais atribuídos à literatura afroamericana é a representação da oralidade na literatura. $O$ chamado Black English Vernacular (BEV), transcrito para o contexto literário, é uma característica importante que tem representado, na maioria das vezes, os afro-americanos que permanecem à margem da sociedade. A representação da oralidade na escrita pode significar, então, uma forma de resistência contra o racismo, como por exemplo, nos poemas de Amiri Baraka, no auge do Black Arts Movement, durante 
as décadas de 1960 e 1970. Contudo, a representação do BEV na escrita (como no caso da poesia de Lawrence Dunbar, em fins do século 19), significou também uma forma de atender às expectativas dos leitores por traços da cultura negra que fossem de fácil reconhecimento e que, portanto, servissem às demandas do mercado - o que, de certa forma, produziu um impacto importante no modo como as obras de literatura afro-americana eram (ou ainda são) selecionadas para publicação. Nessa perspectiva, espera-se, de modo geral, que autores negros possam atender às expectativas por uma relação mais fiel entre linguagem e realismo - como é confirmado por Gene Jarret (2006), ao afirmar que:

As antologias dão a impressão de que a literatura afro-americana deve apresentar protagonistas afro-americanos ao lado de certos temas históricos, de geografias culturais, de discursos políticos ou de subjetividades definidas racialmente. E tais textos são "autênticos" quando seus autores são identificáveis enquanto afro-americanos, não importando se esses autores desejam ou não serem caracterizados desse modo. Esses protocolos contribuem para a ideia de que o cânone, ou o "melhor" da literatura afro-americana, retrata apenas as realidades da vida negra, ou as práticas do que eu chamo de realismo racial (p. 2)

Quando se trata de poesia afro-americana, Jarret (2006) também ressalta que:

[...] estudiosos têm constantemente descrito a poesia afro-americana "sobre" a vida afro-americana em função da "forma" e do "conteúdo," de modo que a "forma" significa esquemas rítmicos, métrica, diç̧ão e sintaxe, enquanto "conteúdo" significa narrativa temática e tropos. Nessas descrições, um tom negativo e/ou de menosprezo circunda a poesia afro-americana que não trata da vida afro-americana. (p. 11)

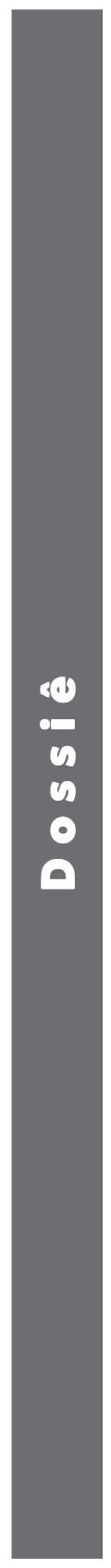


Lauro Maia Amorim. A poesia negra de Harryette Mullen em tradução: ...

Como se nota nos poemas apresentados, Mullen tem se colocado criticamente em relação às expectativas em torno do realismo temático e linguístico na literatura afro-americana. Ela tem problematizado a oposição entre BEV e inglês padrão, uma vez que o último é frequentemente identificado como língua dos "brancos." Em mais de uma entrevista, Mullen recorreu a sua própria biografia para demonstrar o hibridismo que marca a condição de sua formação linguística, lembrando-se que a língua que costumava falar em casa era provavelmente o inglês padrão, ao passo que tinha de aprender a falar BEV enquanto estava com os amigos. Mais tarde, após se graduar na Universidade da Califórnia, em Santa Cruz, Mullen seria influenciada pela representação da oralidade na escrita, promovida pelo Black Arts Movement, e viria a reiterar vários aspectos estéticos ainda prevalecentes entre os poetas afro-americanos dos anos 1970, especialmente em seu primeiro livro Tree Tall Woman. Como professora na Universidade de Cornell e, mais recentemente, em UCLA, familiarizou-se com questões pós-estruturalistas e poesia pósmoderna - experiências que definitivamente influenciaram a sua concepção de negritude e, também, os seus livros mais recentes, como Muse E Drudge e Sleeping with the Dictionary.

Em uma entrevista concedida a Cynthia Hogue, publicada em Postmodern Culture, Mullen afirma que na época em que escreveu Tree Tall Woman era "definitivamente influenciada pelo Black Arts Movement, [pela] ideia de que existia uma cultura negra e de que se podia escrever a partir da posição de se estar numa cultura negra." Por outro lado, acrescenta que "[uma vez que] o projeto [do Black Arts Movement] havia criado um espaço para eu escrever [...] eu não tinha de levar em frente esse projeto, porque ele já havia sido empreendido; eu não tinha que dizer "sou negra, e negro é bonito." $\mathrm{Na}$ verdade, na época em que eu escrevia, isso começava a ficar um pouco repetitivo e até chato" (HOGUE, 1999).

Seu envolvimento com formas poéticas experimentais, incluindo a construção deliberada de uma poesia alusiva, mas também elusiva, representa um questionamento acerca da identidade cultu- 
ral: por que não repensar a negritude como uma forma conectiva e lúdica de se relacionar com a tradição, por meio de uma inovação que amplia seus próprios limites? Trimmings, $S^{*} P e R M^{* *} K^{*} T$, Muse $\mathcal{E}$ Drudge, assim como Sleeping with the Dictionary, parecem ser respostas a esse questionamento, pois retratam questões que envolvem a formação da identidade cultural, incluindo a negritude, o gênero, a comodificação do corpo negro, e os espaços públicos e privados.

Ao longo do tempo, no entanto, Mullen percebeu que questões relacionadas ao público-leitor tornaram-se cruciais para se compreender como sua obra tem sido percebida em relação à inovação e ao que chamamos de blackness. Em uma outra entrevista, ela "desabafa":

[...] tendo publicado Tree Tall Woman, em 1981, eu comecei a recitar poesias do livro, quando então, muitos negros compareciam às apresentações. Havia brancos, morenos e mulatos [brown people], e outras pessoas de cor também. Mas, de repente, quando comecei a fazer leituras públicas de Trimmings [1991] e de $S^{*} P e R M^{* *} K^{*} T$ [1992], eu me tornei a única negra presente no recinto, lendo minha poesia. Eu me via, assim, dentro de uma sala, em que tipicamente não havia qualquer outra pessoa de cor presente - o que era algo, é claro, que eu poderia fazer, e era interessante... Mas não era o que eu necessariamente desejava, e então, pensei "como posso unir todas essas pessoas em uma só sala?" Muse \& Drudge foi minha primeira tentativa na busca de criar esse público. Queria que diferentes leitores de diferentes obras minhas pudessem se convergir. Estava bastante feliz em ver aquelas pessoas, interessadas em inovação formal, começarem a aparecer quando publiquei Trimmings e $S^{*} P e R M^{* *} K^{*} T$, em parte, porque eu estava respondendo, nesses livros, à obra de Gertrude Stein, e, ao mesmo tempo, lidando com minhas próprias preocupações com questões de raça, gênero e cultura. [...] Nunca achei que tivesse me tornado menos negra nesses dois livros ou ficado mais negra em Tree Tall Woman. Mas creio que o modo com que essas coisas são definidas no domínio público é que,

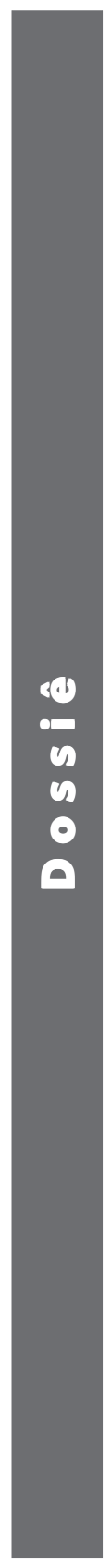


Lauro Maia Amorim. A poesia negra de Harryette Mullen em tradução: ...

de fato, as pessoas viam $S^{*} P e R M^{* *} K^{*} T$ não como um black book, mas como um innovative book. E essa idéia de que ou você é negro ou você é inovador, é algo contra o qual eu realmente estava lutando. E Muse \& Drudge significou a tentativa de mostrar que eu podia fazer as duas coisas ao mesmo tempo. (GRIFFIN, 1997).

Se durante o Black Arts Movement, muitos poetas afro-americanos sentiram a necessidade de uma concepção mais claramente definida de negritude, expressa em poesia com uma linguagem politicamente mais direta, Mullen, especialmente a partir dos anos 1990, "define" negritude em seu trabalho não fundamentada em uma condição identitária essencialista, mas na relação com o que a negritude historicamente tem se tornado. Tradição e herança não são apenas implicadas no processo criativo, mas são transformadas pelo "tornar-se." Nesse sentido, o trabalho de Mullen não seria apenas experimental, mas poderia também ser lido como uma asserção performativa por meio da qual, blackness tem se provado historicamente experimental.

No entanto, em que medida Harryette Mullen pode encontrar-se numa posição paradoxal? Para afirmar a possibilidade de uma inovação formal poética enquanto black poetry, terá ela de ressaltar o que é publicamente reconhecido como black em sua própria escrita elusiva? Ou terá de explorar as dissonâncias no interior da experiência negra para exibir sua alteridade, ou as diferenças no interior dela mesma (ou seja, diferenças em relação aos marcadores reconhecíveis, públicos da negritude)?

Essa questão deverá ser necessariamente do tipo "ou... ou"? A poesia de Mullen é, sem dúvida, uma resposta afirmativa para ambas as perguntas.

\section{Negritude e miscigenação: desafios tradutórios}

Certamente um dos desafios para a tradução da poesia de Mullen (especialmente de Muse E Drudge) para o português inclu- 
em as referências intertextuais ao blues e ao jazz, e à literatura americana e à afro-americana, como por exemplo, no caso do verso contendo o nome de uma personagem escrava, "Topsy" (de A cabana do pai Tomás, de Harriet Beecher Stowe), ou do título de um romance (como Gopher Grapevine, do autor negro Charles Waddell Chestnutt). Além disso, há também os trocadilhos, como "diva road kills," que alude tanto à "estrada da diva (que) mata" quanto aos "animais atropelados na estrada da diva." Há, ainda, trocadilhos construídos em torno de expressões idiomáticas, como, por exemplo, a dramatização sócio-racial entre os personagens "kettle" ("chaleira") e "pot" ("panela"), palavras oriundas da expressão "pot calling the kettle black" ("a panela chamando a chaleira de preta"), que significa repreender alguém por um "defeito" que o próprio repreensor possui.

Os desafios "menos" visíveis para a tradução e publicação da poesia de Mullen no Brasil residem na questão do público-leitor, especialmente quando se leva em consideração as pressuposições sócio-raciais existentes no país, comparadas ao contexto das questões estéticas levantadas pela autora na sociedade americana. Um aspecto complexo seria, assim, o da miscigenação, especialmente quando se considera o modo com que o discurso de Mullen, em relação a sua poesia e à cultura americana, enfatiza a condição constitutiva da miscigenação para ambas. A história da formação cultural de Mullen está em sintonia com a sua visão até certo ponto positiva da miscigenação como uma realidade teórica concreta. Em uma entrevista concedida por ela a Calvin Bedient, isso é notado:

Calvin Bedient: A linguagem em seu poema [Muse \& Drudge] tem, é claro, um aspecto mestiço [mongrel]. Há vários registros diferentes do inglês. Você acha que de certa forma este é um texto branco/negro?

Mullen: Muito já foi dito sobre como a cultura americana é miscigenada, um produto da mistura de diversas raças, culturas e línguas, e eu concordo com isso. Eu diria que sim, que meu texto é deliberadamente multi-vocal, que tenta expres-

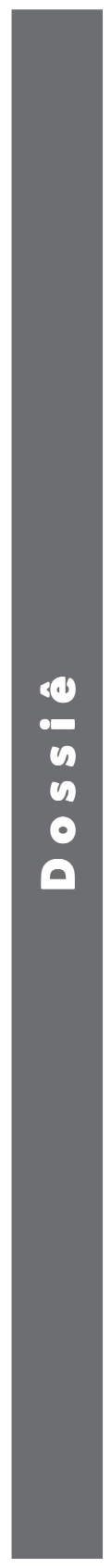


Lauro Maia Amorim. A poesia negra de Harryette Mullen em tradução: ...

sar a diversidade real de minha própria experiência vivida aqui, exposta a diferentes culturas. "Mongrel" ["mestiço", "vira-lata"] vem de "among" ["entre"]. "Among others" ["entre outros"]. Estamos entre; não estamos sozinhos. Somos todos "mongrels." (BEDIENT, 1996, p. 653)

Mullen ressalta a importância da miscigenação nos Estados Unidos e como isso influenciou seu trabalho na direção de uma experimentação poética para além de limites raciais e estéticos preestabelecidos. Em outras palavras, a miscigenação não é, para ela, de modo algum incompatível com a noção de experimentação.

Não é difícil imaginar um espaço comum entre a sua avaliação positiva da miscigenação e o profundo processo de miscigenação no Brasil. A miscigenação tem sido historicamente celebrada no país como a própria fundação da identidade brasileira e, de certa forma, possibilitou a emergência de importantes movimentos estéticos no século 20. É necessário, contudo, fazer uma distinção aqui: Harryette Mullen, na condição de poeta afro-americana, por razões históricas e literárias, pode mais facilmente celebrar a miscigenação como um argumento para explorar e expandir os limites da negritude em sua própria poesia, e, ao mesmo tempo, reafirmar sua condição de mulher escrevendo poesia negra, e confirmar sua dívida para com a experimentação afro-americana, por vezes ignorada, no interior da própria tradição. No entanto, desde a segunda metade do século 20, historiadores e sociólogos, como Munanga (2004), têm criticado o louvor generalizado da noção de miscigenação, demonstrando como ela participa da sustentação do mito da "democracia racial" no Brasil, em nome de uma política que promove a ilusão de um país racialmente pacífico, onde, na realidade, a maioria dos negros e mulatos é sistematicamente marginalizada e excluída de sua cidadania integral. Precisamente por causa disso, a defesa da miscigenação tem sido fortemente criticada por movimentos negros no Brasil.

Por outro lado, atualmente, nos EUA, muitos afro-americanos alcançaram uma visibilidade econômica e social: com o tempo, es- 
pecialmente após o movimento dos direitos civis, a presença de afroamericanos nas camadas da (alta) classe média tem crescido significativamente. Mas também é verdade que muitos dos sem-teto, desempregados ou subempregados nos EUA são constituídos tanto por afro-americanos quanto por pessoas de outras etnias. A despeito das desigualdades sócio-raciais existentes nos EUA, e considerando a emergência social de um número considerável de afro-americanos - o que, de certa forma, afeta positivamente o consumo de produtos culturais, incluindo a apreciação/produção de literatura - é possível imaginar, sem resvalar no determinismo, que a experimentação na poesia de Mullen, assim como seu discurso sobre a miscigenação e a integração de públicos-leitores aparentemente incompatíveis, representam um resultado concreto de reflexões que se tornaram possíveis graças às realizações históricas e sociais de setores significativos da população afro-americana. A esse respeito, podese afirmar, portanto, que o questionamento de identidades essencializadas na literatura afro-americana e a receptividade de diferenças não essencializadas com foco na experimentação (e por que não, na miscigenação e mistura?) tornaram-se possíveis porque ao lado da forte tradição literária afro-americana tem ocorrido uma significativa inclusão econômica e material de sujeitos que, como Mullen e seus atuais e potenciais leitores negros, podem agora expressar seus anseios culturais para além dos limites restritos da sobrevivência.

Por razões históricas e econômicas distintas, parece que uma estética afro-brasileira tenderia a seguir o que Spivak (1997) denominou "essencialismo estratégico", por meio do qual afro-brasileiros teriam que constantemente reafirmar a "essência" da negritude em vista de determinadas razões políticas e estratégicas na busca de uma inclusão social e econômica, e também de uma visibilidade cultural e estética mais profunda. Mas como a poesia de Mullen bem como seu discurso enquanto acadêmica - construídos, em parte, em torno da miscigenação (cultural) - poderiam ser lidos e traduzidos em face da complexidade das questões que a cultura afro-brasileira suscita?

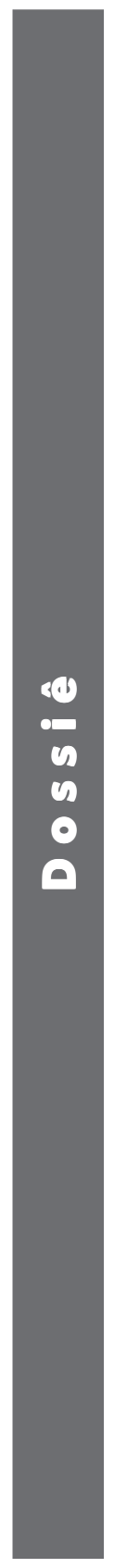


Lauro Maia Amorim. A poesia negra de Harryette Mullen em tradução: ...

Nesse sentido, como tradutor, proponho as seguintes perguntas: de que modo a sua poesia poderia ser lida pelo discurso cultural vigente (inclinado a favorecer a miscigenação como uma concepção integral da identidade nacional), para o qual poderia soar sedutoramente experimental? Isso significaria torná-la "menos negra" para os padrões literários afro-brasileiros?

Mullen problematiza "a ansiedade de se incorporar ou representar a identidade negra autêntica" (MULLEN, 2001, p. 1), e louva a "interrogação exploratória da identidade negra como uma formação discursiva, cultural e social [ao permitir, portanto,] que os significados da negritude se proliferem e se expandam [...], permitindo a instabilidade na definição do que a negritude é" (MULLEN, 2007, p. 2). Traduzir o trabalho de Mullen tendo em vista o público leitor afro-brasileiro, politicamente voltado para uma negritude "afirmativa" - ou melhor, para uma definição mais clara de negritude em face das ambiguidades geradas pela miscigenação -, significará abrir mão da instabilidade que caracteriza a negritude de seus poemas? Ou um gesto que pode frustrar expectativas e disseminar as diferenças (internas) que fazem da negritude um conceito sem fronteiras, mas também em constante construção?

Essas questões representam, portanto, desafios para a tradução da poesia de Harryette Mullen no Brasil. Elas representam menos uma necessidade de respostas definitivas do que uma iniciativa que produza outras questões envolvendo as relações entre tradução e os discursos sócio-raciais existentes no Brasil e os possíveis (des)encontros com os leitores.

\section{Referências}

BEDIENT, C. "The solo misterioso blues: an interview with Harryette Mullen". Callaloo, 19. 3, p. 651-69, Summer, 1996.

FROST, E. "An interview with Harryette Mullen". Contemporary Literature, vol. 41, 3, p. 397-421, Autumn, 2000. 
GRIFFIN, F.; MAGEE, M.; GALLAGHER, M. Conversation with Harryette Mullen. 1997. Disponível em: <http://epc.buffalo.edu/authors/mullen/ interview-new.html>. Acesso em: 7 jul. 2009.

HOGUE, C. "Interview with Harryette Mullen". Postmodern Culture, 9.2b, 1999. Disponível em: <http://referenc.lib.binghamton.edu:2116/journals/ postmodern_culture/v009/9.2hogue.html>. Acesso em: 7 jul. 2009.

JARRET, G. A. (Ed.). African American literature beyond race: an alternative reader. New York: NY University Press, 2006.

MULLEN, H. Recyclopedia: Trimmings, $S^{*} P e R m^{* *} K^{*} T$ and Muse $\mathcal{E}$ Drudge. Saint Paul: Graywolf Press, 2006. 2002.

Sleeping with the dictionary. Los Angeles: University of California Press,

Tree tall woman. Energy Earth Press, 1981.

“What's African about African American poetry?" Fence, 4.1, Spring/ Summer 2001. Disponível em: <http://www.fencemag.com/v4n1/text/ afric_amer.html>. Acesso em: 7 jul. 2009.

"The cracks between what we are and what we are supposed to be: stretching the dialogue of African American poetry". 25 nov., 2007. Disponível em: <http://www.asu.edu/pipercwcenter/how2journal/archive/ online_archive/v1_5_2001/current/in-conference/american-lit/mullen.html >. Acesso em: 7 jul. 2009.

MUNANGA, K. Rediscutindo a mestiçagem no Brasil. São Paulo: Autêntica, 2004.

SPIVAK, G. C."'In a word': Interview". In: ROONEY, E.; NICHOLSON, L. (Ed.) The second wave: a reader in feminist theory. New York: Routledge, 1997. p. 356-78. 